\title{
Living Labs and designed serendipity: collaboratively discovering the UDUBSit \& Mfunzi emerging platforms
}

\author{
Wouter Grove \\ Information Systems, University of the Western Cape, South Africa
}

\begin{abstract}
Recent investigations into the paradoxical notion of designed serendipity position the concept within the research fields of design science, creativity and to a lesser extent digital innovation. In this study we contribute to the work on designed serendipity by analysing the role of the Living Labs methodology in facilitating and enabling serendipity. We specifically investigate that role within the context of two Higher Education cases within an African context. The two cases describe the development of emerging digital platforms co-created within their respective contexts. The UDUBSit mobile application (developed at the University of the Western Cape, South Africa) and Mfunzi mobile application (developed at Mzumbe University, Tanzania) are analysed to determine the extent to which the Living Labs approach enabled observable instances of designed serendipity. This study presents a brief analysis of the causal mechanisms and contextual factors that combine to create designed serendipity within the context of the cases evaluated and within platform design. The study links these causes back to Living Labs as a design methodology.
\end{abstract}

Key words: Living Labs, designed serendipity, emerging platforms

\section{Background}

"Serendipity: 'the discovery through chance by a prepared mind of new findings that were not looked for"' (Merton, I968).

In South Africa there is a popular cultural saying that can be loosely translated as, "your lands must be ploughed and ready when the rain comes", which, much like the old business adage, "fortune favours the prepared" suggests an important underlying design principle: being prepared makes it possible to benefit from serendipity/creativity when it happens. This study describes ways in which the Living Labs design approach prepares the ground for moments of serendipitous creativity during the design process that can occur unexpectedly, much like rain.

Within this African context, there has been a proliferation of new digital platforms (David-West et al. 2016) which have the potential of enabling development by creating first and second order network effects (Eisenmann et al. 201r), and enabling and sustaining 
online communities (Spagnoletti et al. 2015). Most of these digital platforms are fairly young and can be classified as "emerging platforms" - a concept that will be defined later in this study as the developmental changes and evolution of platform elements, architecture and governance over time. Limited extant literature was found describing good design principles when developing new, or emerging, platforms. Within the field of Higher Education Living Labs has been suggested as a suitable design approach.

African Higher Education Institutions (HEIs) recognize the potential of digital platforms as enablers of design products of ICT development. Gastaldi et al. (2015) calls the current decade the fourth Higher Education innovation era, in which HEIs become 'orchestrators of continuous innovation ecosystems' (Gastaldi et al., 2015). In this era the developmental potential of HEIs on the level of ICT hinges predominantly on their ability to design such ecosystems: locally relevant, socially embedded digital platforms that facilitate continuous innovation (Avgerou, 2010).

The Living Labs (LL) research approach (see Era \& Landoni 2014; Schuurman et al. 2015) has been applied with some successes within an HEI context of supporting continuous innovation and digital platform design within HEIs in South Africa (Callaghan \& Herselman, 20I5; Baelden et al., 20I6), and Tanzania (Audenhove, Baelden, et al., 20I4; Hooli et al., 20I6). We will return to these applications of the LL approach shortly when discussing the two focal cases of this study.

The Living Labs approach "seeks to elicit unforeseen user ideas and behaviors to enhance product innovation" (Sauer, 20r6), by "varying routines, being observant, creating mental space, relaxing boundaries, drawing on experience and looking for patterns" (Makri et al. 20I4); a process which often increases the developmental impact of the research in serendipitous ways. It is this link between Living Labs and serendipity that will be investigated in this study.

Recently authors have started to investigate the paradoxical concept of "designed serendipity" (Vanschoren et al., 20I4); with this concept having interesting implications within the research fields of design science, creativity and to a lesser extent digital innovation.

In this study we join the investigation into designed serendipity by analysing the role of the Living Labs methodology in facilitating and enabling serendipity. Our analysis takes place via two digital platforms co-creation/design processes within the African HEI context.

The study is structured as follows. First we clarify the research approach followed by the researchers as a critical review of two case studies within the field of information systems (IS). We then position the two cases as emerging platforms, with a brief overview of current platform design principles available to IS researchers. Third, we describe Living Labs as a suitable design approach for emerging platform design, and fourth we define "designed serendipity". We then describe instances of designed serendipity found in the two cases, followed by a discussion, findings, and recommendations. 


\section{Research Approach}

It has been argued that information systems (IS) research conducted from the "standard" paradigms of positivism and interpretivism, suffers from persistent theorypractice inconsistencies (Longshore Smith, 2006) and it has been argued that a Critical Realist ontology may contribute to overcoming such often-occurring inconsistencies. (Longshore Smith, 2006).

Critical Realism has been viewed as an approach that can play a role in advancing the development of IS knowledge through Design Research (Carlsson, 2007). Critical Realism proposes a focus on causal mechanisms and contextual assumptions, or what researchers call generative mechanisms (Hedstrom \& Swedberg, I996; Carter \& New, 2005; Mutch, 2010).

Similarly, case study analysis has been described as an appropriate method to investigate the causal mechanisms and contextual factors that combine to create sociotechnical factors (Wynn \& Williams 20I2, see table I). In the same vein, Living Labs is also known as a methodology that bridges the theory-practice gap (Era \& Landoni, 20I4).

\section{Evaluating Causal Explanations (derived from Runde 1998)}

\begin{tabular}{l|l}
\hline Causal Test Question & Implications \\
\hline $\begin{array}{l}\text { Are the causal factors of the pheno- } \\
\text { menon actually manifest in the con- } \\
\text { texty? }\end{array}$ & $\begin{array}{l}\text { - Confirm that a cited causal factor was in fact part of } \\
\text { the context of the phenomenon. } \\
\text { - Confirm that explanatory information from generali- } \\
\text { zation (e.g. reference theory) applies to the specific } \\
\text { context. }\end{array}$ \\
$\begin{array}{l}\text { Ensure causal factors are not idealizations; the } \\
\text { causal factor may potentially exist in the realm of the } \\
\text { real and not just as an impossible theoretical entity. }\end{array}$ \\
\hline $\begin{array}{l}\text { If the causal factors were part of the } \\
\text { context, were those factors causally } \\
\text { effective? }\end{array}$ & $\begin{array}{l}\text { - Assess the proposed causal factor to determine if it } \\
\text { is a cause of the phenomenon and not an accidental } \\
\text { or irrelevant feature of a genuine cause. } \\
\text { - Determine if the proposed causal factor was in fact } \\
\text { preceded by another causal factor of the event. }\end{array}$ \\
\hline $\begin{array}{l}\text { Do the causal factors provide a } \\
\text { satisfactory explanation to the } \\
\text { intended audience? }\end{array}$ & $\begin{array}{l}\text { - Ensure the causal explanation is not too remote (un- } \\
\text { specified links in causal chain or adequate knowl- } \\
\text { edge of links cannot be assumed). } \\
\text { - Ensure the causal explanation is not too small such } \\
\text { that it is just one of a composite of causes producing } \\
\text { the observed event. }\end{array}$ \\
\hline $\begin{array}{l}\text { Does the proposed mechanism pro- } \\
\text { vide causal depth? }\end{array}$ & $\begin{array}{l}\text { Assess depth of necessity such that the observed } \\
\text { event would have occurred in the absence of the } \\
\text { proposed causal factor due to the presence of an } \\
\text { alternative causal factor. } \\
\text { - Assess depth of priority to determine if the proposed } \\
\text { causal factor is closely preceded by another causal } \\
\text { factor significant in explaining the event. }\end{array}$ \\
\hline
\end{tabular}

Table 1: Critical realism focuses on causal mechanisms (Wynn \& Williams, 2012). 
In this study we aim to create a practical understanding of the causal mechanisms of designed serendipity within platform design, linking these causes back to Living Labs as a design methodology. To do so we analyse two cases where Living Labs was used as a design methodology; in both cases with the aim of designing emerging platforms for use in a Higher Education context.

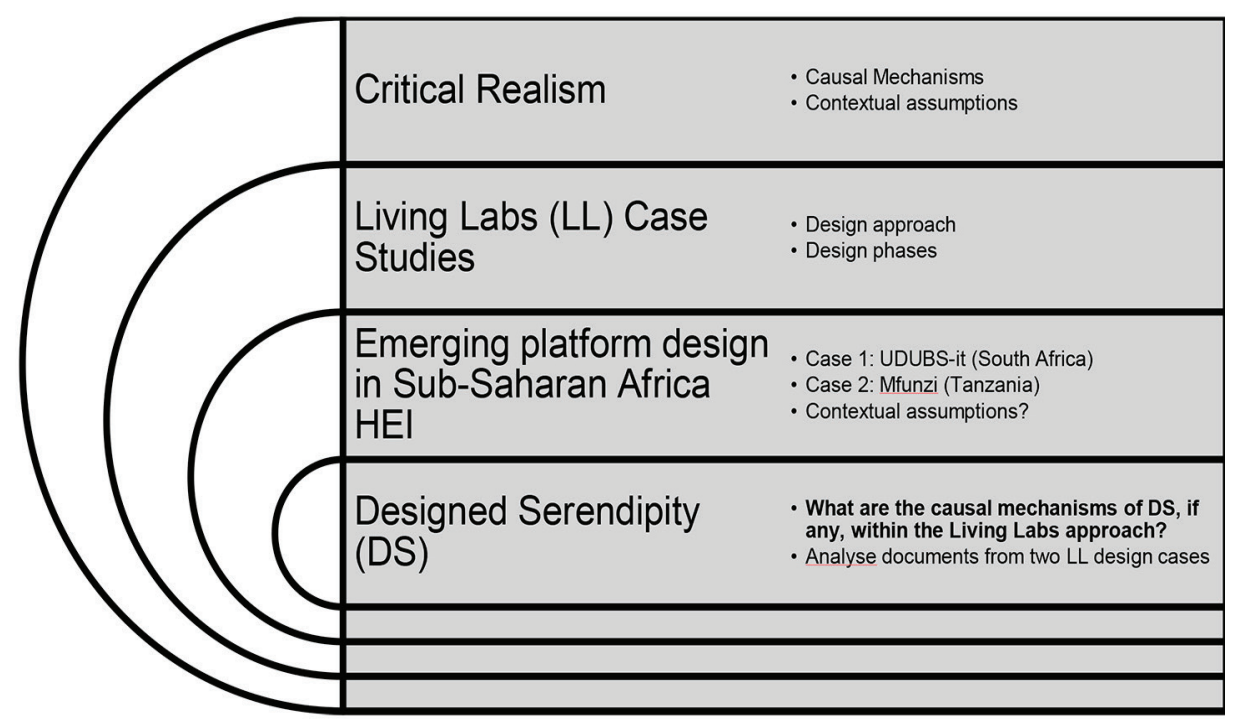

Figure 1 : Summary of focus of this study.

Carlsson (2005) urges researchers conducting studies of this nature to create an understanding of design that can be used across the different fields of design in IS. As Carlsson (2005) explains:

"Using van Aken's (2004) classification we can distinguish three different designs an IS professional makes when developing an IS- initiative: 1) an object-design, which is the design of the IS intervention (initiative), 2) a realization-design, which is the plan for the implementation of the IS intervention (initiative), and 3) a process-design, which is the professional's own plan for the problem solving cycle and includes the methods and techniques to be used to design the solution (IS intervention) to the problem. IS design science research should produce knowledge that can be used by the professionals in the three types of designs" (Carlsson 2005).

As this study relies on a critical analysis of cases to determine causal mechanisms of designed serendipity within platform design, the researchers position the work with the IS body of knowledge as a Critical Realism study. We make use of Case Study analysis to create knowledge of the relationship between Living Labs and the concept of "designed serendipity" that can be used in IS design regardless of the design objective. 


\section{Description of cases}

Two cases are analysed in this study, each describing the design of an emerging platform. We will refer to each case by the name of its resultant platform: (I) Mfunzi being a Tanzanian initiative, with (2) UDUBS-it being its South African counterpart.

The Mfunzi and UDUBS-it mobile applications are both the culmination of several years of collaboration between the University of the Western Cape (UWC), Ghent University, the Vrije University of Brussel (the SMIT-iMinds programme in particular), and Mzumbe University (MU), Tanzania.

The design process of both applications followed a Living Labs- based co-design process where students and staff participated collaboratively in the user needs identification and iterative user testing phases.

The UDUBSit and Mfunzi mobile applications are both unique instantiations of a conceptual design that originated in the field of digital anthropology. The application design is based on the concept of a geographically focused, spatio-temporal grid that mediates interactions between users of the application in an attempt to make information more locally relevant and therefore more conducive to the fostering of useful relationships. Another explicitly stated focus of both of the applications is the building of inclusive local communities.

The cases were chosen because of their longitudinal and potentially revelatory nature. The cases also have clear boundaries, even though it can be viewed as part of a threeparty longitudinal research project (including the Zone-It project and Ghent University, Belgium and the Mfunzi project at Mzumbe University, Tanzania), the UDUBS-it application, as a bounded system, is unique in its geographic focus area, targeted audience base, technology architecture, and various other design elements.

Also both cases used co-creation approaches, and specifically made use of the Living Labs approach, to elicit user input collaboratively from potential and actual user groups.

Co-creation, especially at the early front end of the design process, has been adopted by researchers and practitioners with positive long-range consequences (Sanders \& Stappers, 2008). "Over the past six decades, designers have been moving increasingly closer to the future users of what they design" (Sanders \& Stappers, 2008). However, the design, emergence and development of these platforms specifically within the context of HE in South Africa and Tanzania, as well as the use of co-creation within that process, have been under-explored as yet.

This study presents a brief analysis of the causal mechanisms and contextual factors that combine to create "designed serendipity" within the context of the cases evaluated.

\section{Positioning the cases as emerging digital platforms}

Based on a systematic literature review (Sun et al. 20I6), the following comprehensive definition of IT platforms has been proposed: "An IT-platform is defined as comprised of a technological base on which complementary add-ons can interoperate, following standards and allowing for transactions amongst stakeholders, within the platform-centric ecosystem". 
The platform concept has proliferated in management research (Porch et al. 2015) and attempts have been made to create an integrative framework around technological platforms (Gawer, 20I4). Within the African context, there has also been a proliferation of platform organisations and technologies (David-West \& Evans, 20I6).

Engagement by HE in South Africa and Tanzania around the emerging issue of digital platforms has, however, been so far been relatively poor. The current weaknesses in our understanding of platforms, as socio-technical artefacts within this context, are also evident by the lack of focused research in this regard.

It is necessary for our study to arrive at a clear operational definition of what we in our research group started calling "emerging platforms". The concept of platform emergence, in our minds, refers to the developmental changes and evolution of platform elements, architecture and governance over time. These changes are driven by the intention of the designers of the particular socio-technological system, and their interpretation and translation of the expressed vision of the internal organisational owners of the projects. In the case of both UDUBSit and Mfunzi, the intention of the project owners was to develop a digital application for local community building. The initiators in both cases were university management at the respective institutions.

\section{Emerging platforms}

The issue of platform evolution (or platform emergence, as we have been referring to it) has been specifically analysed in detail by Tiwana (Tiwana et al. 20Io; Tiwana, 20I4). In much of the other platform literature the issues around and dynamics of platform development, growth and evolution have often constituted sub-themes, for example in (Bakos \& Katsamakas, 2008; Gawer et al. 2008; Gawer, 2009, 20I0, 20I4; Boudreau, 20I0; Gawer \& Cusumano, 2013; Parker \& Van Alstyne, 2013; Frattini et al. 20I4; Thomas et al. 2014). It is necessary to delve much deeper into the nature of digital platforms and the dynamics that impact on their emergence. However this is outside the scope of this study.

According to Spagnoletti (Spagnoletti et al., 2015) the development of online communities can assist in fostering customer relationships (with students in the case of HEI), brand building, collection of customer information, improving service delivery (pre-and post-transaction) and the ongoing use of customer feedback to develop products and services more effectively and test new products.

From the initial conception of the Zone-it application (a pre-cursor project to both UDUBSit and Mfunzi) the intention was expressed to develop the application as a platform (Stroeken et al. 20I5). For example, one of the aspects that was highlighted in the co-creation process and Living Labs Needs Analysis study done around the UDUBSit application was the respondent's expressed need for a platform with more integrated, visible and accessible and relevant information (Audenhove et al. 2014; Baelden et al. 2016).

The UDUBSit and Mfunzi mobile applications can be described as emerging platforms because their purpose has been delineated as being community-building within the campus community and the design aim has been the gradual creation of co-created engagement features that are meaningful and significantly useful for participants. A clear 
intention of the platform sponsors (project initiators) in both cases has been to create an engaging platform with interactive and meaningful participation in building the campus community. Both of the cases analysed in this study can therefore be classified as emerging platforms. Both the UDUBSit and Mfunzi projects are currently in launch phases (beta-testing) and already exhibit some elements of digital platforms, although some of these elements are still in the early phases of maturity.

The drivers of platform evolution suggested by Tiwana et al. (2010); Tiwana (2014) may assist us in these two cases under investigation, for example see figure below:

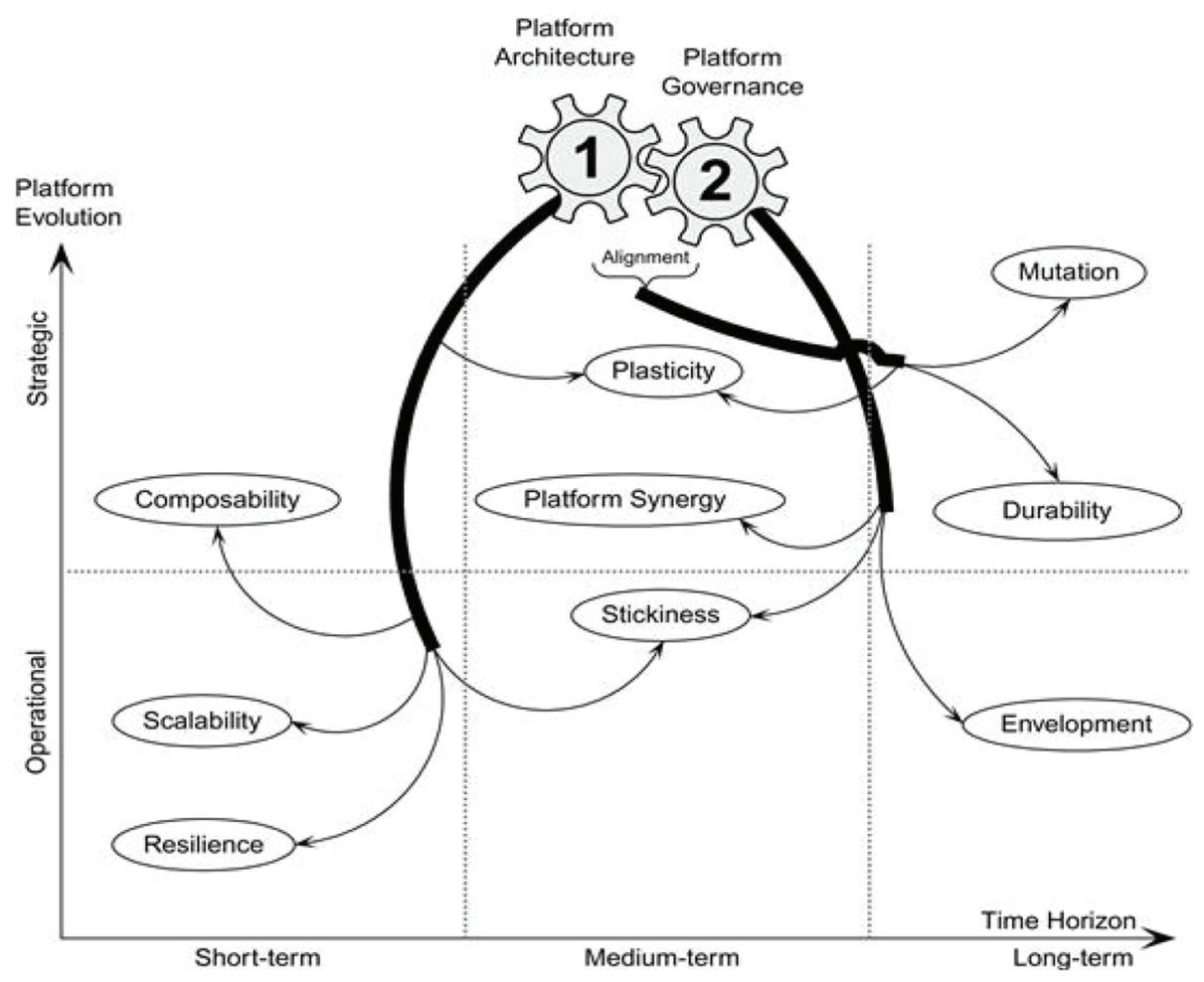

Figure 2: Summary of primary drivers of nine metrics of platform evolution (Tiwana 2014).

Both the UDUBSit and Mfunzi applications are still grappling with design issues around their architecture-governance alignment, scalability and resilience (in terms of Tiwana's definition of these concepts). Both applications still show a lower level of composability as there is still a limited amount of subsystems within the application ecosystem that users can readily integrate with. Tiwana describes the properties of good platform architecture as being: simplicity, resilience, maintainability, and evolvability.

Both the applications studied can be classified as having evolving but immature architectures at present. With the UDUBSit and Mfunzi case, for example, intensive discussions between different internal university role-players have resulted in decisions at 
both universities to outsource the ongoing maintenance aspects of the application (i.e. bug fixing; version maintenance; tweaking of features or user interface elements) due to internal lack of relevant and appropriate software development capacity. Likewise, stickiness is still difficult to evaluate for both applications at this early stage of usage.

The design of successful platforms is not a simple matter. Boncheck and Choudary identify three elements of a successful platform (Bonchek \& Choudary, 2013), namely:

- Connection: how easily others can plug into the platform to share and transact

- Gravity: how well the platform attracts participants, both producers and consumers

- Flow: how well the platform fosters the exchange and co-creation of value

Information Systems and Design professionals in HE are increasingly being called upon to design and implement Digital Platforms. This is also true for the project teams tasked with bringing to fruition the vision of the project owners and initiators at both UWC and Mzumbe University.

Although both emerging platforms have not yet attracted a large enough user base for us to be able to make clear deductions about its success in creating connection, gravity and flow, we believe that a better understanding of the ability of these platform projects to facilitate "designed serendipity" may be a useful early indicator of the future capability to achieve these platform design goals.

\section{Living Labs}

Within specifically European and American contexts, Living Labs (LL) have been developing rapidly over the last few years as a method and approach for enabling user co-designed open innovation processes (Schuurman 20I5). LL in so-called developing countries has also been investigated (Weiss 2012), as well as in South Africa in particular (Gumbo et al. 20I2).

Living Labs have also been applied within the higher education context internationally (See for example Graczyk (2015) and in South Africa (See for example Audenhove et al. (20I4). Living Labs as a mechanism for innovation has drawn significant attention and it has been applied through various organisational and innovation ecosystems (Almirall et al. 20I2). Living Labs has however received limited attention in the literature (Era \& Landoni 20I4). Living Labs has been applied within the South African context (Botha et al. 20I2; Coetzee et al. 20I2; Herselman et al. 2010; Smit et al. 20II; Pitse-Boshomane et al. 2008; Adam et al. 20II). For a recent report of LL application within the South African context see Cunningham \& Cunningham (2016). For a critical discussion of the limitations of the Cunningham 2016 report, see Weiss (2012).

According to the integrative definition proposed by Era \& Landoni (20I4) LL can be defined as follows: "A Living Lab is a design research methodology aimed at co-creating innovation through the involvement of aware users in a real-life setting." According to Era \& Landoni (2014) this definition aligns with one of the original proponents of Living Labs, namely William 
Mitchell from MIT (Boston), Medialab and School of Architecture and City Planning. This definition is also referred to extensively by for example Schuurman et al. (2015). This definition describes Living Labs as "a user-centric research methodology to sense, prototype, validate and refine complex solutions in multiple and evolving real-life contexts." See Era \& Landoni (20I4) for a comprehensive summary of various other definitions of the concept of LL.

Era \& Landoni (20I4) further describes LL as "an emerging public-private partnership (PPP) concept in which firms, public authorities and citizens work together to create, prototype, validate and test new services, businesses, markets and technologies in real-life contexts, such as cities, city regions, rural areas and collaborative virtual networks between public and private players."

In the innovation research landscape, LL can be positioned as a methodology between the user-centered design approach and the participatory paradigms (Era \& Landoni 20I4). The positioning and value of LL as structuring mechanism for user involvement in innovation development has been investigated by Schuurman (2015). The necessity to create clearer conceptual models around LL that are grounded in existing, more established innovation theories has been expressed by Schuurman (2015). For a recent and comprehensive literature review of the LL field, see Schuurman et al. (2015).

Living Labs have previously been linked with the notion of serendipity by (Sauer \& De Rijke, 20I6). The LL approach "seeks to elicit unforeseen user ideas and behaviors to enhance product innovation". We will now evaluate the manner in which the application of the Living Labs approach in each of our two case studies have contributed to the creation of designed serendipity by first positioning each case as an application of the Living Labs approach and then presenting examples of designed serendipity in each case.

\section{Living Labs phases}

In our analysis of LL-enabled serendipity, we were also interested in identifying which design phase was most likely to include serendipitous design moments. Towards this end, we identified in which of the four phases of LL, as defined by Pierson \& Lievens (2008) the serendipity occurred:

"The living lab research cycle contains a number of phases, including:

I. contextualization (defining research focus and framework, and identifying potential users),

2. concretization (describing the everyday life of the recruited respondents in relation to the innovation that is being studied and in some cases co-design research),

3. implementation (experimental implementation of the innovation), and

4. feedback and evaluation (research on the attitudes of the user sample and the identification of technological recommendations). This final phase can then be used as input for a second iterative cycle of living lab research"

\section{Living Labs in HEls in Sub-Saharan Africa}

The Living Labs (LL) research approach (see Era \& Landoni 20I4, Schuurman et al. 20I5) has been applied within this context of supporting continuous innovation and digital platform design within HEIs in South Africa (Callaghan \& Herselman, 2015; Baelden et al., 20I6) and Tanzania (Audenhove et al., 20I4; Hooli et al., 20I6). 


\section{Serendipity}

Serendipity, sometimes referred to as "the art of making an unsought finding" (Van Andel I994), underlies many significant discoveries (André et al., 2009).

In his seminal article on serendipity, Van Andel (I994) brings the concept of serendipity into contact with research and design, stating that, "systematic, directed (re)search and serendipity do not exclude each other, but conversely, they complement and even reinforce each other. In practice it is not by design or by serendipity, but rather by design and by serendipity, and/or vice versa" (Van Andel I994).

In Makri and Blandford's first article on serendipity in an information sciences context (20I2), serendipity is described as "a process of making a mental connection that has the potential to lead to a valuable outcome, projecting the value of the outcome and taking actions to exploit the connection, leading to a valuable outcome".

André (et al. 2009) allude to an aspect of serendipity that is missing from Makri and Blandford's definition: the possibility of actors being prepared for the advent of a serendipitous moment, stating that, there are ways in which the "inventor's perception may be enhanced to increase the opportunity for serendipity".

Moving towards designed serendipity, André (et al. 2009) conclude their article on serendipitous results in an information seeking context by suggesting three ways of preparing for (supporting) serendipity: (I) presenting content at the appropriate time, (2) supporting creativity and play, and (3) mitigating the cost of extra information.

\section{What is designed serendipity?}

Recently authors have started to investigate the paradoxical concept of "designed serendipity" stating: "Designed serendipity and a dynamic division of labour occur naturally when ideas, questions, data, or tools are broadcast to a large group of people in a way that allows everyone in the collaboration to discover what interests them, and react to it easily and creatively. As such, for online collaborations to scale, online tools must make it practical for anybody to join and contribute any amount at any time" (Vanschoren et al., 2014).

Makri and Blandford (2012a; 20I2b) present a model that is useful for our analysis of serendipity within a Living Labs context. In this model, an event is given a rating according to its (i) unexpectedness, (ii) insightfulness, and (iii) value, with the three ratings giving the researcher a way of determining the strength of the serendipity related to the event.

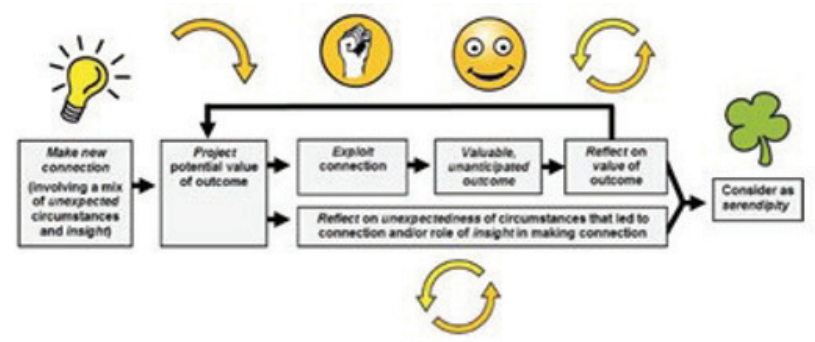

Figure 3: Empirically-grounded process model of serendipity (Makri \& Blandford, 2012b). 
The above mentioned model suggests a classification of serendipitous moments based on their unexpectedness, insightfulness, and the value added quality as a result of the serendipity. We used this model as the basis of our analysis, adding LL variables discussed in the next section.

\section{Analysis}

Our analysis of the relationship between $\mathrm{Ll}$ and serendipity with an emerging platform design context was specifically built on the intersection of LL literature and Makri and Bladford's model (2012). We evaluated all available design process documentation (primarily in Audenhove et al. 2014; Audenhove, Fourie et al. 2014) within our two case studies and proposed finding evidence (observations) of serendipity. We classified and evaluated our observations in an attempt to evaluate the LL-serendipity relationship along the following metrics:

- In which LL phase did the observation occur?

- Was it Unexpected? (Somewhat (S) or Very(V))

- Was it Insightful? (Somewhat $(\mathrm{S})$ or Very $(\mathrm{V})$ )

- Was it Valuable? (Somewhat (S) or Very(V))

- What was the Strength of serendipity ((Likert scale $\mathrm{I}=$ none, $5=$ very strong)

- $\quad$ Did LL play a role in facilitating/enabling the serendipity? (Yes/No) If Yes, How can the role of LL be described? (LR: Enhancing local relevance; SE: Enhancing social embeddedness; CI: Enhancing continuous innovation)

- What was significance of the role of LL? (Likert scale $\mathrm{I}=$ none, $5=$ very significant)

- Contextual notes

\section{Instances of designed serendipity in Living Labs cases}

Through a documentary analysis of user testing processes and Living Labs process phases, various pieces of evidence was found that indicated the occurrence of "serendipitous moments". Using our analysis framework as described above, we now list these occurrences in two tables, one for each case. 


\begin{tabular}{|c|c|c|c|c|c|c|}
\hline 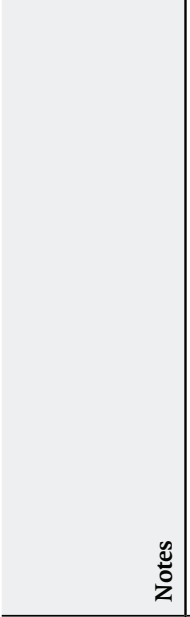 & 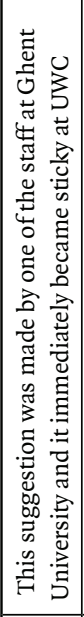 & & 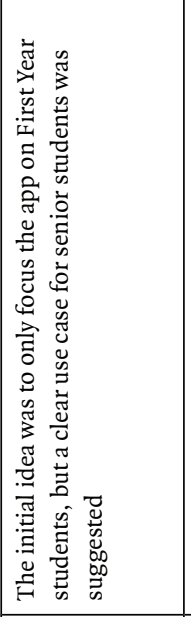 & 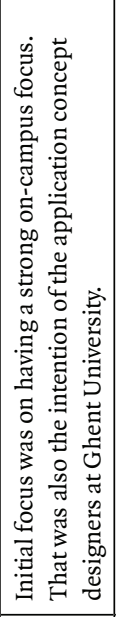 & 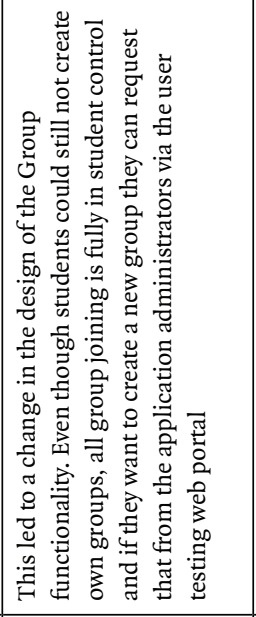 & 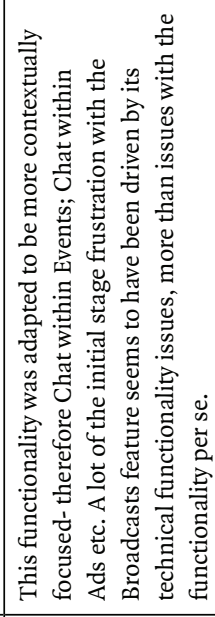 \\
\hline 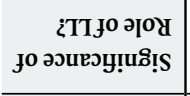 & + & + & + & + & + & in \\
\hline 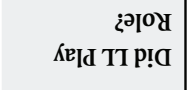 & આ્త & $\begin{array}{l}\text { ப் } \\
\text { 离 }\end{array}$ & $ت$ & 我 & $\begin{array}{l}\text { س } \\
\ddot{y} \\
\text { y }\end{array}$ & $\begin{array}{l}\text { ț } \\
\text { î }\end{array}$ \\
\hline 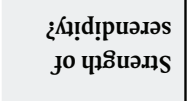 & + & + & + & + & $\sigma$ & in \\
\hline 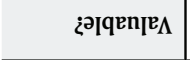 & $>$ & $>$ & $>$ & $>$ & $>$ & $>$ \\
\hline 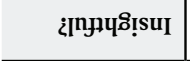 & is & $>$ & $>$ & $>$ & $>$ & $>$ \\
\hline ¿рәцәәdхәи & $>$ & is & is & is & is & $>$ \\
\hline әsеЧd TT & 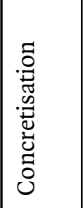 & 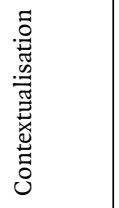 & 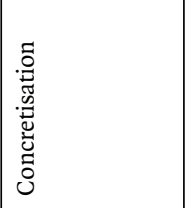 & 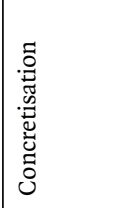 & 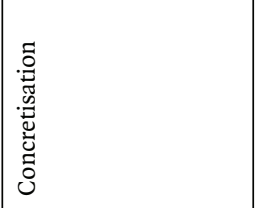 & 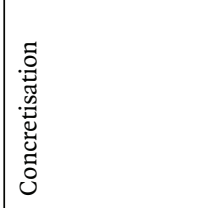 \\
\hline 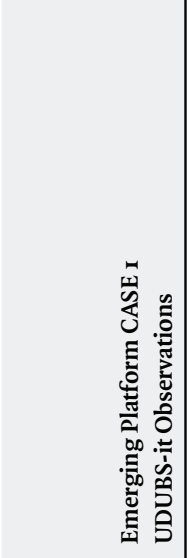 & 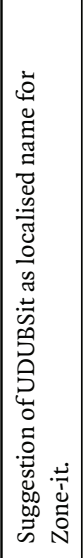 & 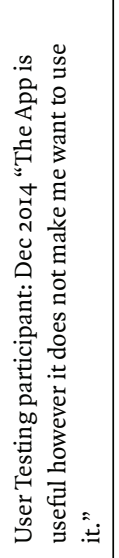 & 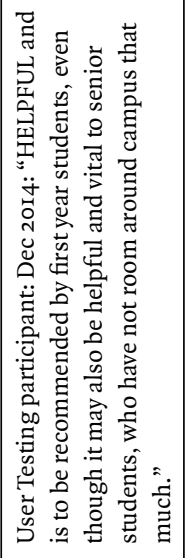 & 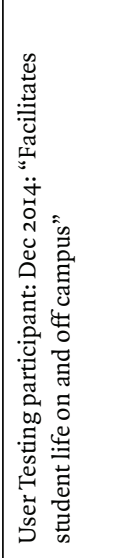 & 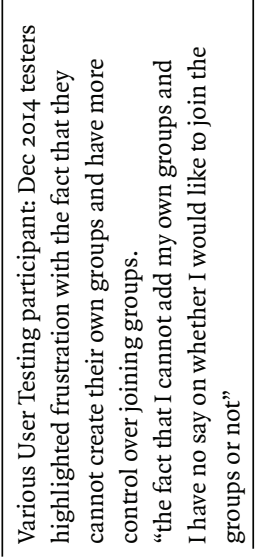 & 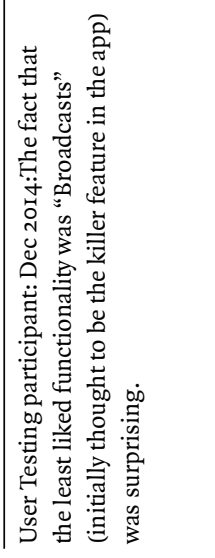 \\
\hline
\end{tabular}




\begin{tabular}{|c|c|c|c|c|}
\hline ¿ّ̊ & 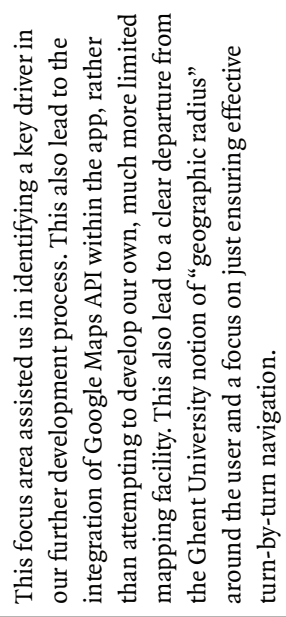 & 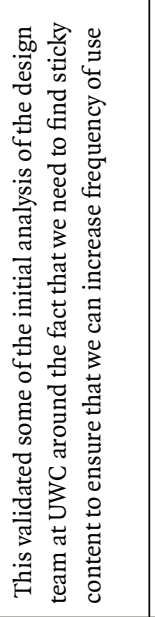 & 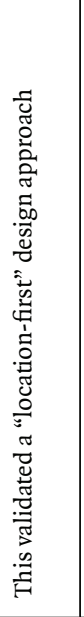 & 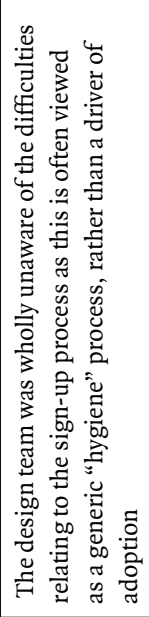 \\
\hline 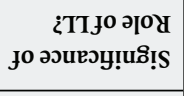 & + & + & + & + \\
\hline 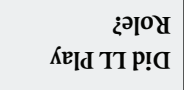 & 엽 & $\Xi$ & 躳 & $\begin{array}{l}\vec{U} \\
\text { 嵌 }\end{array}$ \\
\hline 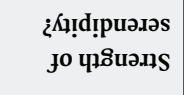 & $m$ & $m$ & in & + \\
\hline 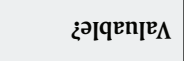 & $>$ & $>$ & $>$ & $>$ \\
\hline 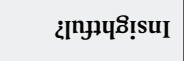 & is & is & $>$ & $>$ \\
\hline ¿рәцәәdхәи & es & is & $>$ & $\infty$ \\
\hline әsечd TT & 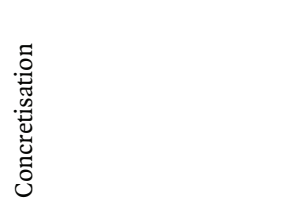 & 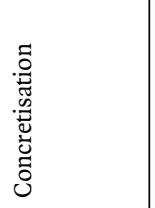 & 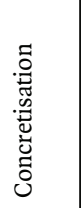 & 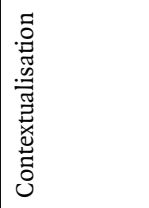 \\
\hline 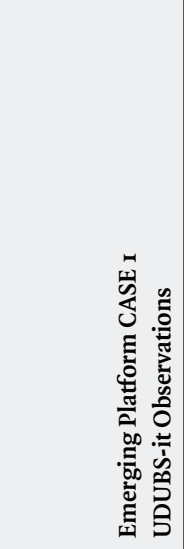 & 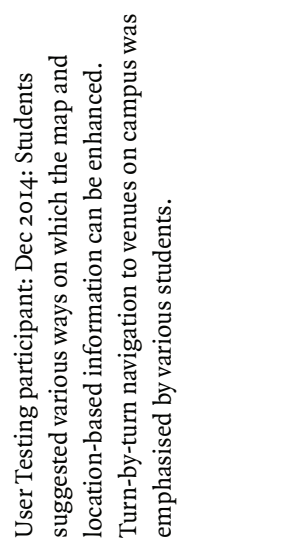 & 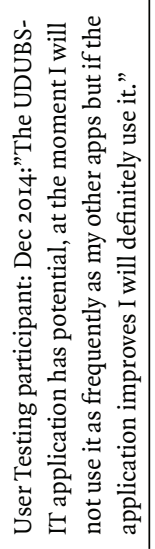 & 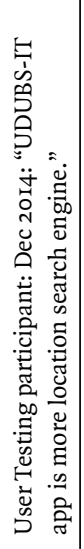 & 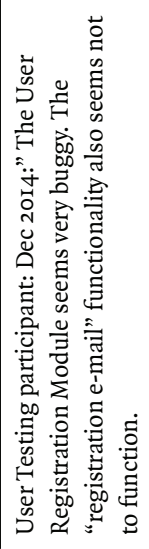 \\
\hline
\end{tabular}




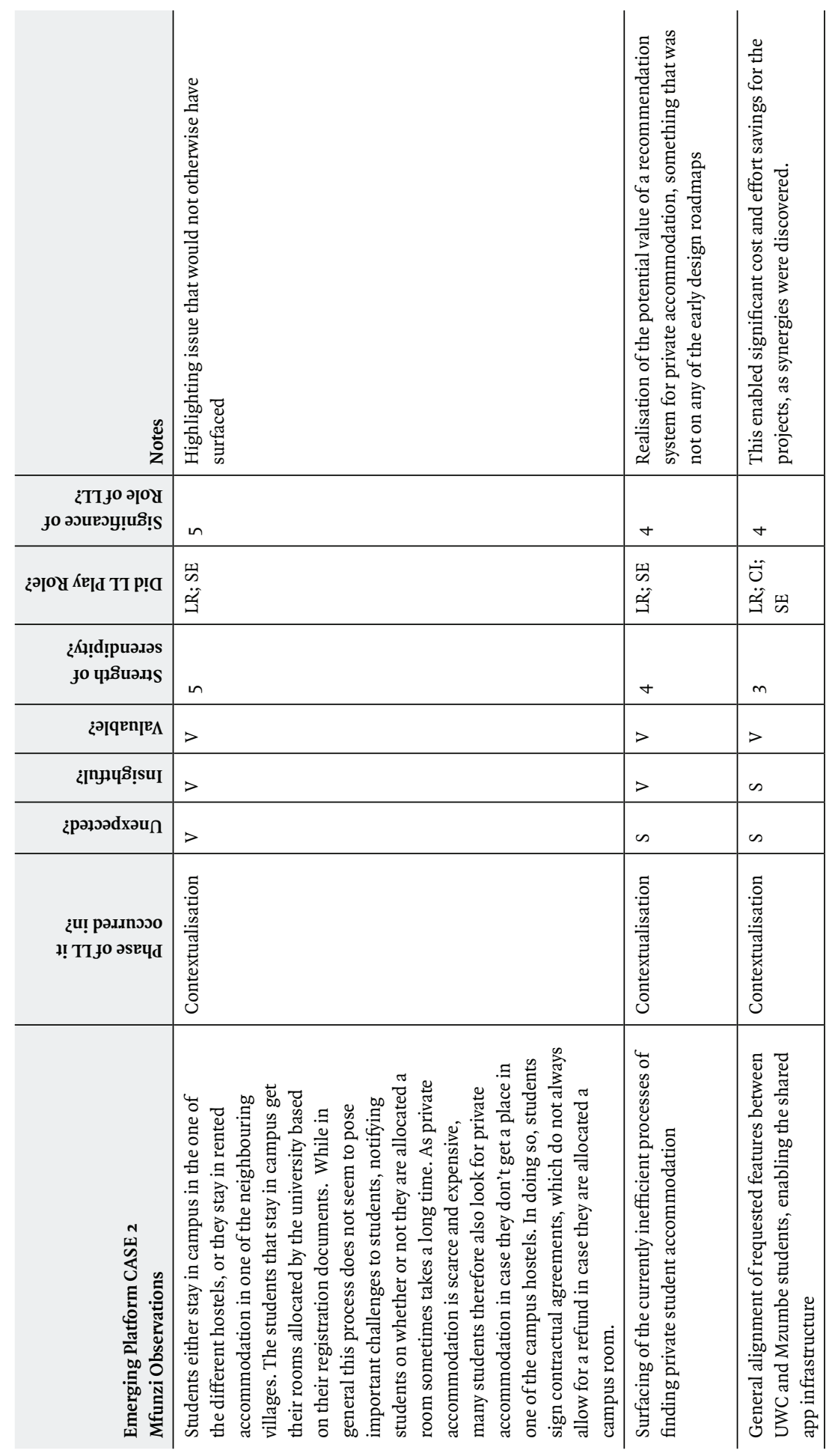




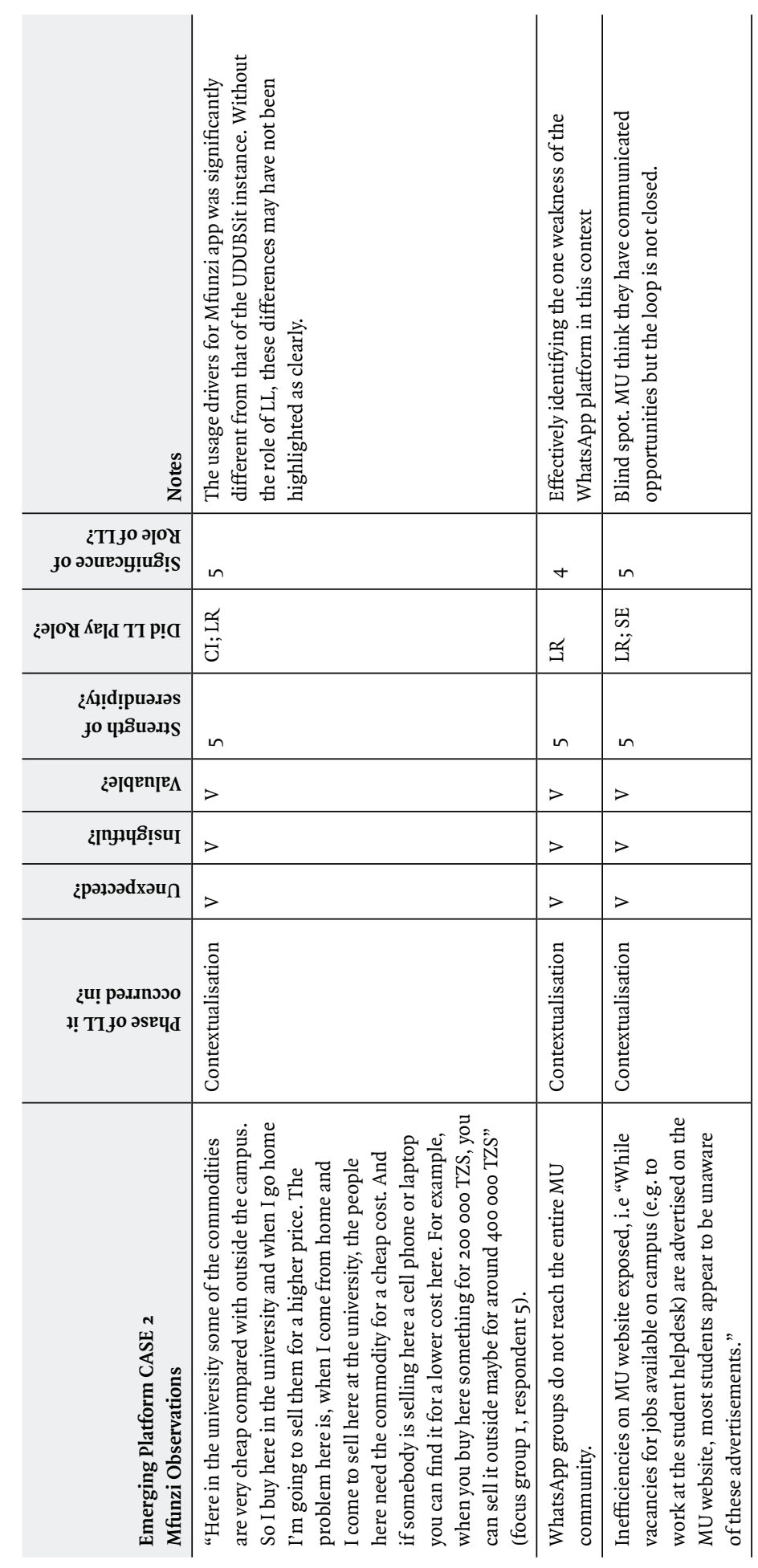




\begin{tabular}{|c|c|c|c|c|}
\hline 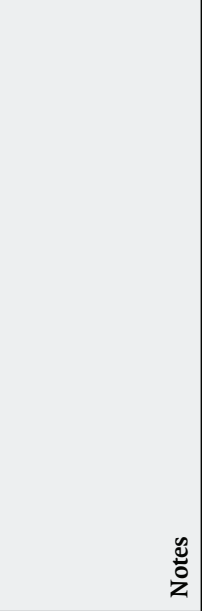 & 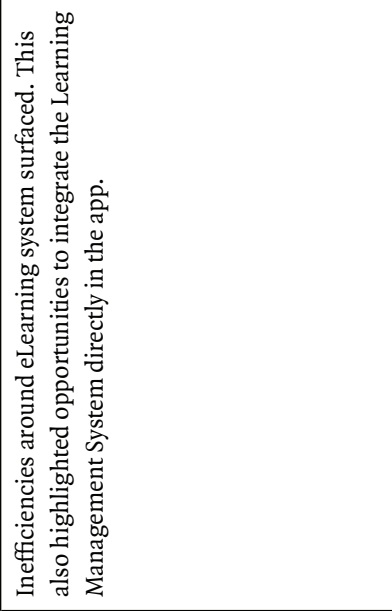 & 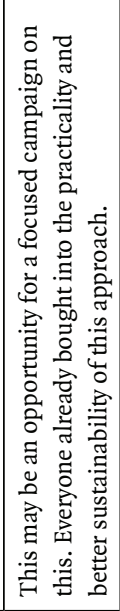 & 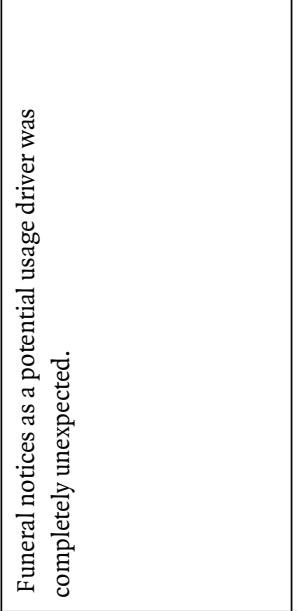 & 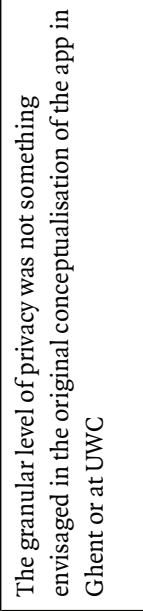 \\
\hline 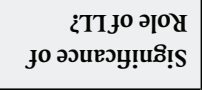 & in & $\ln$ & in & in \\
\hline 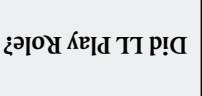 & $\begin{array}{l}\text { 岀 } \\
\ddot{ٌ} \\
\ddot{G}\end{array}$ & 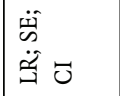 & 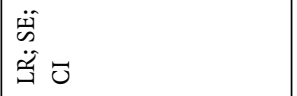 & 뗙 \\
\hline 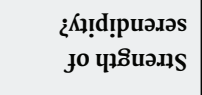 & in & in & in & in \\
\hline 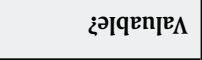 & $>$ & $>$ & $>$ & $>$ \\
\hline 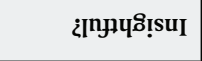 & $>$ & $>$ & $>$ & $>$ \\
\hline ¿рәцәәdхәи & $>$ & $>$ & $>$ & $>$ \\
\hline 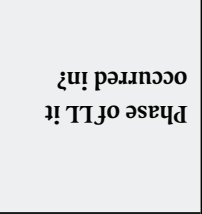 & 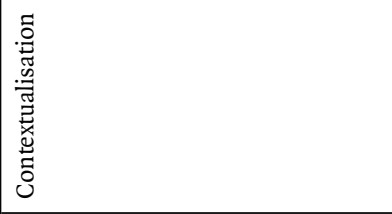 & 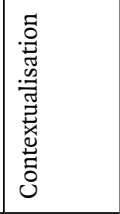 & 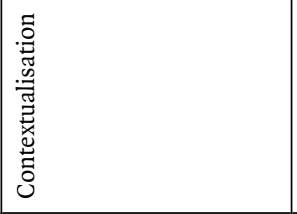 & 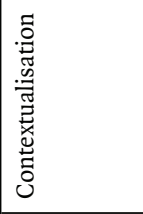 \\
\hline 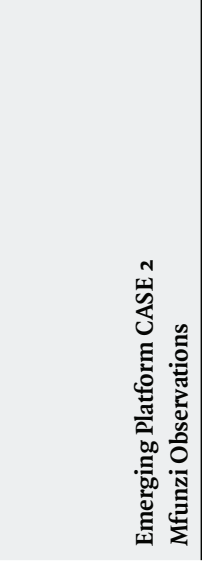 & 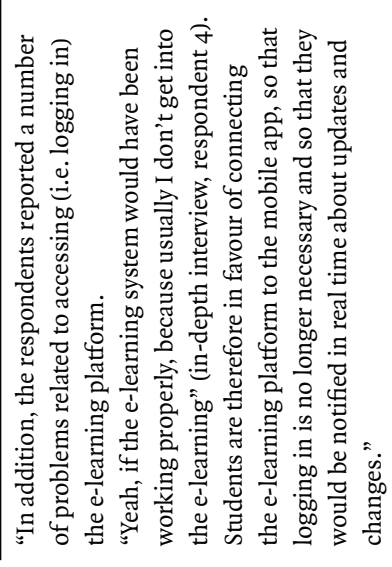 & 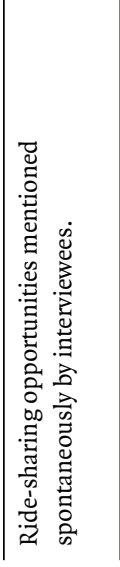 & 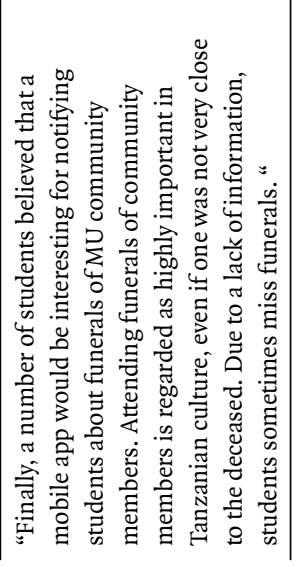 & 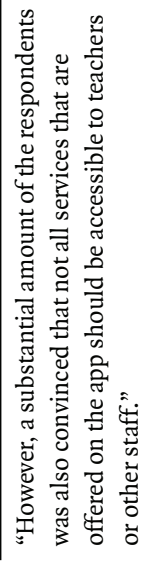 \\
\hline
\end{tabular}




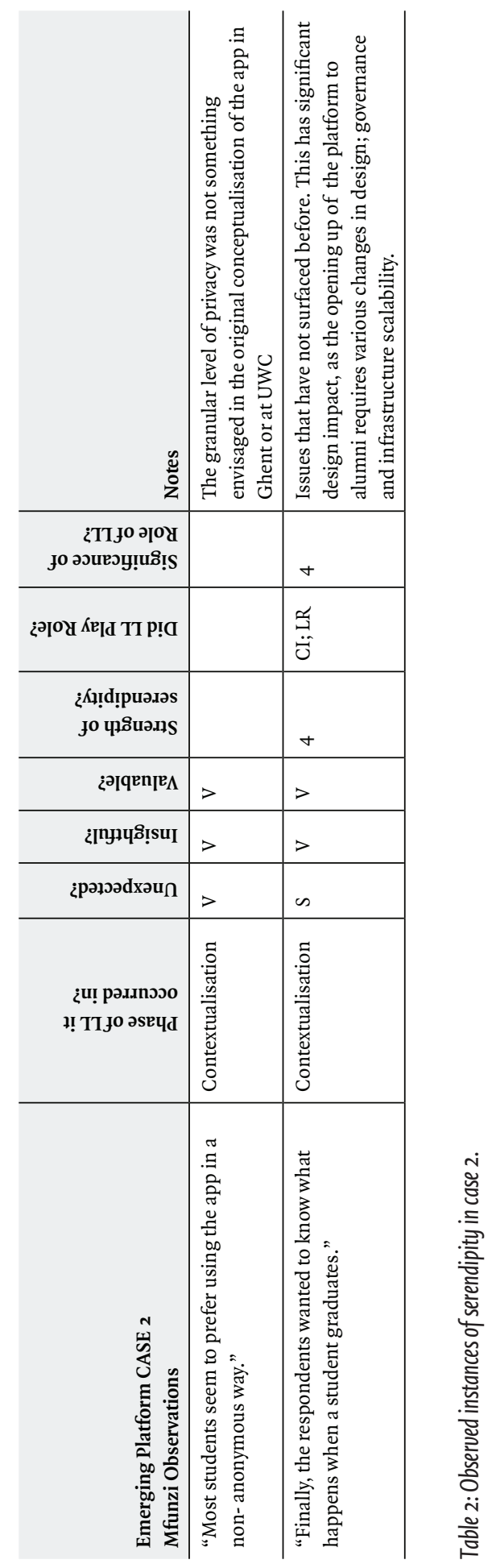




\section{Discussion}

Upon analysis of the instances of "unsought findings" in both the cases under investigation, it became clear that in both the South African and Tanzanian contexts, ample evidence of serendipitous moments during the LL process was observed.

In the case of Mfunzi, all observations took place in the Contextualisation phase of the LL process. This is understandable given the early stage in the maturity life cycle of that emerging platform. Students at Mzumbe were not yet interacting with the digital artefacts during the user testing and design process, but mainly with paper prototypes.

In the instance of UDUBSit, serendipitous moments were observed during both the Contextualisation and Concretisation phases, which is again not unexpected as that instance of the emerging platform is technologically more mature. Students interacted with paper prototypes during the Contextualisation phase and with first versions of the Android application during the Concretisation phase.

It is interesting to note that, in the case of UDUBSit there did not seem to be a significant change in the number or nature of "serendipitous moments" observed in both the LL phases. The fact that the observations of serendipity occurred independent of whether a digital artefact was present, seems to indicate that the process of engagement was driving the presence of serendipity, rather than the artefacts per se.

In the case of UDUBSit, 30\% of the observations were viewed as VERY UNEXPECTED and $70 \%$ as SOMEWHAT UNEXPECTED. $70 \%$ of observations were viewed as VERY INSIGHTFUL. In the case of Mfunzi, $75 \%$ of observations were viewed as VERY UNEXPECTED. All observations, except one were viewed as VERY INSIGHTFUL and all observations were classified as VERY VALUABLE.

The role of LL was viewed as being very significant in most of the observations. To bring our analysis closer to finding possible causal mechanisms of DS within LL, we attempted to identify what value the DS added to the design process by using three LL focus areas as identifiers. The added value aimed towards: (CI) enhancing Continuous Innovation within the design process, (SE) enhancing the Social Embeddedness within the design process, and/or (LR) enhancing the Local Relevance of the design/process. The researchers acknowledge that no empirical grounds exist for making such a classification, but contend that it was a necessary step in satisfying the requirements of critical realism: causal mechanisms (discussed in the next section) must be viewed within the boundaries of the design approach and within the boundaries of contextual assumptions.

In our analysis of the given observations in both cases we have seen evidence of unexpected insights with value to design teams being generated as part of LL processes. In both cases we have observed insights being created that seemed to contribute to processes of design for better local relevance, better social embeddedness and the facilitation of continous innovation. In the Mfunzi case, serendipity seemed to have a particularly high level of occurrence when LL focused on increasing local relevance. 


\section{Findings}

It has been suggested that design science should either address an unsolved problem in a unique and innovative way or a solved problem in a more effective or efficient manner (Hevner et al. 2004). According to Botha et al. (2012) the use of LL in order to evaluate design artefacts is suitable as, firstly, LL results in practical experimentation through pilot implementations and offers real-life settings which balances richness of contextual complexity with limited and manageable scope. Secondly, LL enables immediate domain-expert feedback and facilitates iterative build-and-evaluate loops. Thirdly, the LL provides an approach that can provide proof of concept of innovative ideas.

The mechanisms through which LL seems to be facilitating designed serendipity can be summarised as follows:

\section{Creating of a context-relevant safe process space for participants to innovate around both solved and unsolved problem, also including previously unseen or unknown problems.}

The mechanisms by which LL fosters innovation have been described as creating a platform for open innovation; fostering a user driven research methodology and functioning as an experimental setting (Sauer, 2013). In the cases discussed the LL approach added value on all three these levels.

The LL process with its inherently participative nature also seemed to place more emphasis on the design process than the artefact. This is in stark contrast with the more traditional and typical Technology Transfer approach (Baelden et al., 20I6). By creating space for serendipity by being inherently participative and open, the LL approach may be more applicable in the context of the design of emerging digital platforms (especially if platforms are viewed as complex emergent socio-technical systems, rather than as technological artefacts only). Deliberately fostering serendipity in participation in early stages can potentially have more effect, as many of the design elements are still malleable. It follows that fostering serendipity in the early stages may have largest potential impact.

In the context of HEI, LL create open inter-disciplinary environments where participants can, in collaborative processes interrogate challenges and solutions (Callaghan \& Herselman, 20I5). Some of the drivers for LL success that have been identified include "clear focus/vision, strong leadership, self-sustainability, a strong sense of community-owned challenges and the potential for sustainable community development" (Callaghan \& Herselman, 20I5).

\section{Creating a collaborative atmosphere and environment that prepares participants} for the advent of serendipitous moments.

André et al. (2009) highlights the fact that, if discoverers are not able to link together and make sense of chance occurrences, they will not arrive at valuable insights. The LL approach's open and inclusive mechanism seems to create a structured, yet open approach that enhances sense-making of serendipitous occurrences.

LL also seem to offer a potentially effective tool with which to prepare participants to be prepared for the "advent of a serendipitous moment" which is suggested by (André 
et al., 2009) as an essential element in facilitating serendipity. LL seems to offer support for designed serendipity by means of (I) presenting content at the appropriate time, (2) supporting creativity and play, and (3) mitigating the cost of extra information (André et al., 2009).

\section{Deepening local relevance and social embeddedness}

The LL approach seems to have been beneficial in creating unexpected insights into practical ways in which emerging platform design elements can be adapted to benefit local relevance and social embeddedness.

\section{Maintaining focus on critical design process drivers}

The LL approach seems to have been beneficial in generating some unexpected findings (and subsequent designer insights) around critical drivers of platform success, such as comments made by participants on the way in which to adapt the emerging platforms to better foster connection, flow and gravity; as per the definitions of (Bonchek \& Choudary, 2013). Facilitating user focus on the drivers of socio-technical system success (but with the freedom to explore boundaries) during design processes may yield some direct benefits such as cost and time savings.

\section{Recommendations}

Involving users in the innovation processes leading to new ICT services is often challenging (Følstad, 2008). LL has been viewed as a particularly promising approach due to the opportunity it provides for obtaining direct user feedback at a relatively large scale of users at different levels of development, as well as the fact that it empowers users as co-creators (Følstad, 2008).

The mechanisms, methods and techniques of the LL approach seem to offer potential in terms of empowering users to increase the likelihood of unsought findings. Even though this is an exploratory study, we have found that serendipity can add benefit to LL processes particularly on the levels of enhancing community ownership, local relevance and enhancing of sustainability.

The LL approach has seemed to spark some serendipitous moments that transferred quickly to practical and useful insights for platform designers. What is particularly promising is the fact that a number of these insights were created around factors that are critical to platform success.

Our findings seems to support the findings of (Sauer \& De Rijke, 20r6) that the LL process enabled improvisational practice, leading to both useful and expected findings, as well as serendipitous findings that can be characterised as useful yet not foreseen. Their study focused on the context of creative retrieval in broadcast media production and also dealt with the role of LL in the early development phases of a new technology.

Our findings also align with that of André et al. (2009) that proposes a more formal consideration of serendipity in design of digital artefacts, stating that "there is a richer space for design to support serendipitous creativity, innovation and discovery than has been tapped to date." 
It will be beneficial to better understand the causal mechanisms of serendipity throughout the LL life cycle in various contexts. This study only focused on the Contextualisation and Concretisation phases. The true value realisation of serendipity and the insights it may bring to designers will only be visible when the emerging platforms are more mature.

An important element of unlocking value from serendipitous moments is the sagacity to make use of those encounters in a productive way (André et al., 2009). If we look at the number of serendipitous revelations advanced by participants that have been included in the further design road map of both the Mfunzi and UDUBSit applications, it does seem that the LL approach may offer some value in making use of the serendipitous encounters in a productive way. Serendipity without insight has little value in emerging platform design. Therefore this promising link is encouraging and suggests that further research be done around this aspect.

The exact mechanisms by which serendipitous moments can be focused on particular design goals are not well understood at present. A more in depth analysis of the particular drivers of serendipity through the LL approach may be beneficial to innovation projects.

There is a risk however that designers view serendipity as a static concept rather than a continuum of potential unsought findings. In applying the LL approach in the design of emerging platforms, designers should aim to enhance the likelihood and potential for serendipity and insight. This can be done by, for example, looking at what it means to have a prepared mind and creating and supporting an infrastructure to support discovery (André et al., 2009).

The LL process offers a structured and tested approach to prepare the ground for serendipitous findings to be enabled through collaborative user innovation.

It is worth noting, however, that in the words of Andel (I994) "Serendipity plays a supporting but essential role, that should not be underestimated or exaggerated."

\section{References}

Andel, P. Van. (1994). Anatomy of the unsought finding. Serendipity: Orgin, history, domains, traditions, appearances, patterns and programmability. British Journal for the Philosophy of Science. 45(2):63I-648.

André, P., Schraefel, M. c., Teevan, J. \& Dumais, S.T. (2009). Discovery is never by chance: Designing for (Un) Serendipity. Proceeding of the seventh ACM conference on Creativity and cognition - C\&C'09. 305.

Audenhove, L. Van, Baelden, D., Musabila, A. \& Bizyuk, T. 20I4. Zone-IT : A location-based \& community oriented mobile application for Mzumbe University , Tanzania: Results from the needs analysis and co-design study .

Audenhove, L. Van, Fourie, L., Njenga, J.K., Adams, R., Debandt, A., Manolache, A., Vekov, D. \& Adams, R. 20I4. Zone-IT : A location-based \& community oriented mobile application for the University of the Western Cape, South Africa: Results from the needs analysis and co-design study. Brussels.

Baelden, D., Van Audenhove, L., Grove, W., Njenga, J., Craffert, L. \& Stroeken, K. 20r6. UDUBSit . A Location Based Mobile Application for the University of the Western Cape A Living Lab Approach in Support of Participatory ICT4D. In P. Cunningham \& M. Cunningham (eds.). IIMC International Information Management Corporation IST-Africa 20r6 Conference Proceedings. I-Io. 
Bakos, Y. \& Katsamakas, E. (2008). Design and Ownership of Two-Sided Networks : Implications for Internet Platforms. 25(2):17I-202.

Bonchek, M. \& Choudary, S.P. (2013). Three Elements of a Successful Platform Strategy. Harvard Business Review. (January 3I).

Botha, A., Herselman, M., Smith, R. \& Coetzee, H. (2012). Design Science and Living Lab Research for Innovation and Development in South Africa. African Journal of Science, Technology, Innovation and Development. 4(3):197-2I4.

Boudreau, K. (2010). Open Platform Strategies and Innovation : Granting Access vs . Devolving Control. 56(I0):I8491872.

Callaghan, R. \& Herselman, M. (20I5). Applying a Living Lab methodology to support innovation in education at a university in South Africa. The Journal for Transdisciplinary Research in Southern Africa. II(I):2I38.

Carlsson, S. (2007). Developing Knowledge Through IS Design Science Research. Scandinavian Journal of Information Systems. I9(2):75-86. [Online],

Available: http://iris.cs.aau.dk/tl_files/volumes/volumeı//no2/Carlson.pdf.

Carter, B. \& New, C. (2005). Making realism work: Realist social theory and empirical research. B. Carter \& C. New (eds.). Routledge.

David-West, O. \& Evans, P.C. (2016). The Rise of African Platforms: A regional Survey. New York.

Eisenmann, T., Parker, G. \& Van Alstyne, M. (20II). Platform envelopment. Strategic Management Journal. 32(I2):I270-I285.

Era, C.D. \& Landoni, P. (2014). Living Lab : A Methodology between User-Centred Design and Participatory Design. 23(2):I37-I54

Følstad, A. (2008). Towards a Living Lab for the development of online community services. The Electronic Journal for Virtual Organizations and Networks: "Special Issue on Living Labs". Io(August):47-58.

Frattini, F., Bianchi, M., Massis, A. De \& Sikimic, U. (2014). The Role of Early Adopters in the Diffusion of New Products : Differences between Platform and Nonplatform Innovations. 3I(3):466-488.

Gastaldi, L., Appio, F.P., Martini, A. \& Corso, M. (2015). Academics as orchestrators of continuous innovation ecosystems: towards a fourth generation of CI initiatives. In Nijmegen, NL: introductory paper for the special issue from 2013 CINet conference International Journal of technology Management. I-20.

Gawer, A. (2009). Platform dynamics and strategies: from products to services. In A. Gawer (ed.). Cheltenham, UK: Edward Elgar Publishing Platforms, Markets and Innovation. 45-76.

Gawer, A. (2010). Towards a General Theory of Technological Platforms.

Gawer, A. (20I4). Bridging differing perspectives on technological platforms: Toward an integrative framework. Research Policy. 43(7):I239-I249.

Gawer, A. \& Cusumano, M.A. (2013). Industry Platforms and Ecosystem Innovation. Journal of Product Innovation Management. 3I(3):417-433.

Gawer, A., Cusumano, M.A. \& Gawer, A. (2008). How Companies Become Platform Leaders. (49201).

Hedstrom, P. \& Swedberg, R. (1996). Social Mechanisms. Acta Sociologica. 39(3):28I-308.

Hevner, A.R., March, S.T., Park, J. \& Ram, S. (2004). Design Science in Information Systems Research. MIS Quarterly. 28(I):75-I05.

Hooli, L., Jauhiainen, J.S. \& Lähde, K. (2016). Living Labs and knowledge creation in developing countries : Living Labs as a tool for socio-economic resilience in Tanzania. African Journal of Science, Technology, Innovation and Development,. 8(I):6I-70. [Online], Available: http://www.tandfonline.com/doi/full/10.1080/20421338.2015.1132534.

Longshore Smith, M. (2006). Overcoming theory-practice inconsistencies : Critical realism and information systems research. Information and Organization. I6:IgI-2II.

Makri, S. \& Blandford, A. (2012a). Coming across information serendipitously - Part 1: A process model. Journal of Documentation. 68(685):684-705. 
Makri, S. \& Blandford, A. (2012b). Coming across information serendipitously: Part 2 - A classification framework. Journal of Documentation. 68(5):706-724.

Mutch, A. (2010). Technology, Organization, and Structure: A Morphogenetic Approach. Organization Science. 2I(2):507-520. [Online], Available: http://www.jstor.org/stable/27765980.

Parker, G. \& Van Alstyne, M. (2013). Platform Strategy \& Open Business Models. MIT Centre for Digital Business.

Pierson, J. \& Lievens, B. (2008). Configuring Living Labs For A “Thick” Understanding Of Innovation. In Ethnographic praxis in industry conference proceedings. II4-I27.

Porch, C., Timbrell, G. \& Rosemann, M. (20I5). Platforms: A Systematic Review OfThe Literature Using Algorithmic Historiography. ECIS 2015 Completed Research Papers. (Paper I43):I-17. [Online], Available: http://aisel.aisnet.org/ecis2015_cr/I43.

Sanders, E.B.N. \& Stappers, P.J. (2008). Co-creation and the new landscapes of design. CoDesign. 4(I):5-18.

Sauer, S. (2013). User innovativeness in Living Laboratories: Everyday user improvisations with ICTs as a source of innovation. University of Twente.

Sauer, S. (20r6). A Living Lab Approach to Understanding Creative Retrieval in Broadcast Media Production. 989992.

Sauer, S. \& De Rijke, M. (2016). A Living Lab Approach to Understanding Creative Retrieval in Broadcast Media Production. In Pisa, Italy SIGIR 'I6 (July I7 - 2I, 2016). 989-992.

Spagnoletti, P., Resca, A. \& Lee, G. (2015). A design theory for digital platforms supporting online communities: a multiple case study. Journal of Information Technology. I-I7.

Sun, R., Gregor, S. \& Keating, B. (2016). Information Technology Platforms: Conceptualisation and a Review of Emerging Research in IS Research. In Adelaide Australasian Conference on Information Systems 2015. I-I7.

Thomas, L.D.W., Autio, E. \& Gann, D.M. (2014). Architectural Leverage: Putting Platforms in Context. Academy of Management Perspectives. 28(2):198-219.

Tiwana, A. (20I4). Platform Ecosystems: Aligning Architecture, Governance, and Strategy. First ed. Waltham, MA: Morgan Kaufmann Publishers.

Tiwana, A., Konsynski, B. \& Bush, A.A. (2010). Dynamics Platform Evolution : Coevolution of Platform Architecture, Governance, and Strategy. (September 2015).

Vanschoren, J., van Rijn, J.N., Bischl, B. \& Torgo, L. (20I4). OpenML: Networked Science in Machine Learning. ACM SIGKDD Explorations Newsletter. I5(2):49-60.

Wynn, D. \& Williams, C.K. (2012). Principles for Conducting Critical Realist Case Study Research in Information Systems. MIS Quarterly. 36(3):787-810. 